\title{
Korean Guidelines for Diagnosis and Management of Interstitial Lung Diseases: Part 5. Connective Tissue Disease Associated Interstitial Lung Disease
}

\author{
So-My Koo, M.D. ${ }^{1, *(\mathbb{D})}$, Song Yee Kim, M.D., Ph.D. ${ }^{2, *(\mathbb{D})}$, Sun Mi Choi, M.D. ${ }^{3}$ (i) and \\ Hyun-Kyung Lee, M.D., Ph.D. ${ }^{4}$, on behalf of Korean Interstitial Lung Diseases Study Group \\ ${ }^{1}$ Division of Allergy and Respiratory Medicine, Department of Internal Medicine, Soonchunhyang University Seoul Hospital, \\ Soonchunhyang University College of Medicine, Seoul, ${ }^{2}$ Division of Pulmonology, Department of Internal Medicine, Severance \\ Hospital, Institute of Chest Diseases, Yonsei University College of Medicine, Seoul, ${ }^{3}$ Division of Pulmonary and Critical Care \\ Medicine, Department of Internal Meidicine, Seoul National University Hospital, Seoul, ${ }^{4}$ Division of Pulmonary and Critical \\ Care Medicine, Department of Internal Medicine, Inje University Busan Paik Hospital, Busan, Korea
}

Connective tissue disease (CTD) is a collection of disorders characterized by various signs and symptoms such as circulation of autoantibodies in the entire system causing damage to internal organs. Interstitial lung disease (ILD) which is associated with CTD is referred to as CTD-ILD. Patients diagnosed with ILD should be thoroughly examined for the cooccurrence of CTD, since the treatment procedures and prognosis of CTD-ILD are vary from those of idiopathic interstitial pneumonia. The representative types of CTD which may accompany ILD include rheumatoid arthritis, systemic sclerosis (SSc), Sjögren's syndrome, mixed CTD, idiopathic inflammatory myopathies, and systemic lupus erythematous. Of these, ILD most frequently co-exists with SSc. If an ILD is observed in the chest, high resolution computed tomography and specific diagnostic criteria for any type of CTD are met, then a diagnosis of CTD-ILD is made. It is challenging to conduct a properly designed randomized study on CTD-ILD, due to low incidence. Therefore, CTD-ILD treatment approach is yet to been established in absence of randomized controlled clinical trials, with the exception of SSc-ILD. When a patient is presented with acute CTD-ILD or if symptoms occur due to progression of the disease, steroid and immunosuppressive therapy are generally considered.

Keywords: Lung Disease, Interstitial; Connective Tissue Disease; Asian Continental Ancestry Group; Guidelines as Topic; Diagnosis; Disease Management; Lung

Address for correspondence: Sun Mi Choi, M.D.

Division of Pulmonary and Critical Care Medicine, Department of Internal Meidicine, Seoul National University Hospital, 101 Daehak-ro, Jongno-gu, Seoul 03080, Korea

Phone: 82-2-2072-4915, Fax: 82-2-762-9662, E-mail: sunmich81@gmail.com

Address for co-correspondence: Hyun-Kyung Lee, M.D., Ph.D.

Division of Pulmonary and Critical Care Medicine, Department of Internal Medicine, Inje University Busan Paik Hospital, 75 Bokji-ro, Busanjin-gu, Busan 47392, Korea

Phone: 82-51-890-6847, Fax: 82-51-890-6341, E-mail: goodoc@gmail.com

*So-My Koo and Song Yee Kim contributed equally to this work.

Received: Feb. 1, 2019, Revised: Apr. 8, 2019, Accepted: Apr. 10, 2019, Published online: May. 31, 2019

(c) It is identical to the Creative Commons Attribution Non-Commercial License (http://creativecommons.org/licenses/by-nc/4.0/). 


\section{Introduction}

Connective tissue disease (CTD) is a disorder characterized by diverse symptoms and signs as autoantibodies circulate in the system, causing damage to internal organs. Interstitial lung disease (ILD) associated with CTD is called CTD-ILD.

At an early stage in diagnosing ILD, it is very important to examine the patient with respect to the existence of various causes of ILD. Of the known causes of ILD, CTD is the most crucial. If ILD is diagnosed in a CTD patient and conversely, if CTD is diagnosed in an ILD patient, CTD-ILD is diagnosed. It is very critical to determine the existence of CTD in ILD patients, because there are significant differences between CTDILD and idiopathic interstitial pneumonia (IIP) in terms of both treatment approach and prognosis. Some CTD-ILD patients present with ILD prior to the CTD diagnosis. Therefore, even in those not previously diagnosed with CTD, any clinical symptoms suggestive of CTD, autoantibody test, and chest Xray findings should be thoroughly checked to determine the existence of CTD.

\section{Classification and Clinical Features of CTD-ILD}

The incidence and clinical features of CTD-ILD differ depending on the form of the associated CTD. Across various types of ILD, the incidence of systemic sclerosis (SSc) is the highest, followed by idiopathic inflammatory myopathies (IIM), rheumatoid arthritis (RA), systemic lupus erythematous (SLE), and Sjögren's syndrome.

\section{RA associated ILD}

ILD is the most common among RA-associated lung diseases, but the prevalence varies depending on the patient group or diagnostic method ${ }^{1}$. A wide range of RA associated ILD (RA-ILD) prevalence rates, $19 \%-44 \%$, has been reported in prospective studies using chest high resolution computed tomography (HRCT) ${ }^{2-5}$, because each author used different ILD definitions and diagnostic methods. A cross-sectional study in which chest HRCT was performed at an RA clinic regardless of respiratory symptoms reported an ILD prevalence of $19 \%$. In the study, chest HRCT had a higher sensitivity in diagnosing ILD than pulmonary function tests (PFT) ${ }^{6}$.

Although RA is more common among women, RA-ILD is reported to be more common in men. Some studies reported a male-to-female ratio of 2:1,8. Typically, it occurs in patients in their 40s and 50s, and age and smoking history are known risk factors of $\mathrm{ILD}^{9-11}$. Rheumatoid factor and anti-cyclic citrullinated peptide were also found to be strongly associated with the occurrence of ILD $^{12-18}$. In RA-ILD, the most common pathological finding in surgical lung biopsy is usual interstitial pneumonia (UIP) ${ }^{19}$.

\section{SSc associated ILD}

SSc, also called scleroderma, has a lower incidence but a higher level of pulmonary infiltration compared with RA. Pulmonary function abnormalities due to ILD are observed in as high as $70 \%$ of SSc patients, and about a third of the patients show clinically significant evidence of ILD ${ }^{1}$. Chest HRCT is essential for diagnosing SSc associated ILD (SSc-ILD), and the most common chest HRCT finding is non-specific interstitial pneumonia (NSIP) ${ }^{20}$. In general, ILD is common in patients with diffuse SSc, a condition in which internal organs as well as the skin are involved, and the autoantibody profile was found to correlate with pulmonary infiltration ${ }^{21-23}$. The autoantibody most commonly found in patients with diffuse SSc is anti-topoisomerase I, also known as anti-scl-70. It has been reported that ILD occurred in $85 \%$ of anti-scl- 70 positive patients and that the antibody concentration level was correlated with the severity and activity of ILD ${ }^{24,25}$.

Fibrotic NSIP is the most common pattern in the pathological findings of SSc-ILD, and cellular NSIP is found in less than $10 \%$ of patients. Typical features of idiopathic pulmonary fibrosis, such as severe fibrosis and fibroblastic foci, are observed in less than $30 \%$ of cases with UIP ${ }^{26-28}$.

SSc-ILD patients are at greatest risk for ILD progression in the first 3-4 years $(45 \%-55 \%)$, and some patients show rapid pulmonary function decline during this time. Accordingly, PFT should be performed on a regular basis. Treatment should be considered in SSc-ILD patients under the following conditions: (1) if at the time of the initial diagnosis of ILD, ILD involvement exceeds $20 \%$ in chest HRCT, or forced vital capacity (FVC) is less than $70 \%$ of the predicted value in PFT, or (2) if diffusing capacity of the lungs for carbon monoxide (DLCO) is over $15 \%$ or FVC over $10 \%$ in a follow-up PFT ${ }^{6,29}$.

SSc-ILD in conjunction with pulmonary arterial hypertension (PAH) is a major cause of death among SSc patients ${ }^{30}$. SSc accompanied by ILD and PAH was found to have 5 times higher mortality risk than that of SSc accompanied by PAH alone $^{31}$.

\section{Sjögren's syndrome associated ILD}

Studies have reported that pulmonary infiltration occurs in $9 \%-24 \%$ of all patients with Sjögren's syndrome, and that abnormal findings in PFT, bronchoalveolar lavage (BAL), and chest HRCT were observed in $75 \%$ of patients with asymptomatic Sjögren's syndrome ${ }^{32-35}$. Generally, pulmonary infiltration manifests in the end stage of Sjögren's syndrome and rarely occurs as the first manifestation ${ }^{36}$.

In Sjögren's syndrome, not only interstitial tissues in the lung but the entire respiratory system could be infiltrated, and so the patient could also present with small airway disease such 
as follicular bronchiolitis, aside from ILD. In whatever form, 10-year mortality increases by more than 4 times in Sjögren's syndrome patients with pulmonary infiltration compared to those without ${ }^{32}$.

NSIP is the most common pathological finding. Studies have found NSIP in $28 \%-61 \%$ of all patients with the syndrome, and additionally, lymphocytic interstitial pneumonia (LIP) in $17 \%^{37,38}$.

\section{Mixed connective tissue disease associated ILD}

Mixed connective tissue disease (MCTD) was defined in 1972 for the first time, and there is still a controversy around this category. Generally, it refers to an autoimmune disease with positive anti-U1 ribonucleoprotein antibody. Pulmonary infiltration is quite common in MCTD, found in $47 \%-78 \%$ of patients ${ }^{39,40}$. According to the literature, severe ILD occurred in approximately $19 \%$ of MCTD patients, and it was associated with anti-Ro-52 antibody but not with disease duration or smoking history ${ }^{41,42}$.

\section{IIM associated with ILD}

IIM include polymyositis (PM), dermatomyositis (DM), and clinically amyopathic dermatomyositis, in each of which a varying degree of skin, muscle, joint, and lung infiltration is present. IIM associated with ILD (IIM-ILD) shows a variety of disease progression patterns from asymptomatic to rapidly progressive ${ }^{43,44}$. The prevalence of ILD in IIM is also found to vary considerably, between $20 \%-78 \%$, and comorbidity and mortality rates are reported to generally increase if ILD co-exists ${ }^{45-48}$. In IIM-ILD versus other CTD types, ILD more frequently occurs as the very first manifestation before it progresses to a systematic disease $e^{49-52}$.

Antisynthetase syndrome (AS) is a specific subset of IIM, with positive antisynthetase antibodies associated with protein synthesis. It is a syndrome characterized by the cooccurrence of ILD and the presence of some of the following manifestations: fever, joint pain, Raynaud's phenomenon, and mechanic's hands. Of various muscle-specific antibodies, antiJo-1 antibody is most commonly used in the diagnosis. As can be seen in the inclusion of ILD as an essential element in diagnosing AS, the importance of ILD in assessment of prognosis is also great. Like other types of IIM-ILD, AS-ILD too shows diverse disease progression patterns. It has been reported that approximately $50 \%$ of patients develop acute respiratory failure $^{51,33,54}$

\section{SLE associated with ILD}

In SLE, pulmonary infiltration occurs in as high as $33 \%-50 \%$ of patients. But, in most patients, the entire respiratory system (thoracic cavity, lung parenchyma, airway, and pulmonary vessels) is infiltrated, and pulmonary infiltration of the pattern shown in ILD tends to be relatively infrequent $(1 \%-15 \%)$ compared to other types of $\mathrm{CTD}^{43,55,56}$. It has been reported that the longer the duration of SLE (over 10 years), the higher the risk of ILD ${ }^{57}$ and that SLE is strongly associated with ILD in the presence of Raynaud's phenomenon, positive response to anti-U1 RNP antibody, sclerodactyly, nailfold capillary loops, and old age $\mathrm{e}^{58,59}$.

\section{Diagnosis of CTD-ILD}

\section{Assessment of disease history and the presence of CTD}

\section{1) Patients already diagnosed with CTD}

If ILD co-occurs in patients already diagnosed with CTD based on CTD diagnostic criteria, it is relatively easy to make a diagnosis of CTD-ILD. But the possibility of ILD occurring due to a drug used to treat CTD or infection should be exclud$\mathrm{ed}^{3,35,60-63}$.

\section{2) Patients never diagnosed with CTD}

In some patients, ILD appears as the first manifestation among diverse clinical features of CTD. Such cases are most commonly observed in IIM (approximately 10\%-30\%), and additionally, the pattern is reported in some RA patients, and also in SSc patients though very rare ret,65 $^{64}$.

If a patient without notable disease history rapidly develops dyspnea over several weeks to several months and eventu-

Table 1. Core manifestations in ILD patients to diagnose underlying CTD $^{66}$

\begin{tabular}{|ll|}
\hline \multicolumn{1}{|c|}{ Organ } & \multicolumn{1}{c|}{ Manifestations to check } \\
\hline Peripheral circulation & Raynaud phenomenon \\
& Sclerodactyly (Figure 1C) \\
& $\begin{array}{l}\text { Digital ulcerations or scars } \\
\text { Telangiectasia (Figure 1D, E) }\end{array}$ \\
& Gottron's sign \\
& Heliotrope rash around the eyes \\
& $\begin{array}{l}\text { Heliotrope rash in the neck, upper chest } \\
\text { and shoulder area (Figure 1F) }\end{array}$ \\
& Photosensitivity \\
& Mechanics' hands \\
Joint & Joint pain, joint swelling \\
& Morning stiffness (over 60 minutes) \\
Muscle & Muscle aches, muscle weakness \\
Mouth and eye & Dry mouth, dry eye (Sicca syndrome) \\
\hline
\end{tabular}

ILD: interstitial lung disease; CTD: connective tissue disease. 
ally experiences respiratory failure while chest HRCT shows a ground glass opacity that is gradually progressing, the possibility of CTD-ILD should be considered. Particularly, if the level of muscle enzymes (e.g., creatinine phosphokinase, and aldolase) increases, IIM should be suspected as the underlying disease ${ }^{65}$. Even in cases with chronic ILD, CTD could be the underlying disease. Hence, whether or not the patient presents any symptom or other manifestation suggestive of CTD, this possibility should be considered (Table 1) ${ }^{66}$. For instance, Raynaud's phenomenon, dry eye and mouth, and muscle weakness tend to have low specificity, but the specificity of mechanic's hands (Figure 1A) or Gottron's papules (Figure 1B) is high. Thus, if mechanic's hands or Gottron's papules are present, DM is highly likely to be an underlying disease ${ }^{67}$. Such systemic symptoms or other manifestations that raise a suspicion of CTD often occur in women under age $50^{68-71}$.

\section{Radiologic findings (chest HRCT findings)}

It is not possible to differentiate IIP and CTD-ILD based on radiologic findings. CTD-ILD often manifests itself in NSIP or organizing pneumonia (OP), or LIP (albeit rare) (Figure 2AC), and IIP most often manifests itself in UIP (Figure 3). Thus, if a typical UIP is not found in an imaging test, CTD is likely to be the underlying disease ${ }^{60}$. An exception is that a radiologic finding of UIP is the most common in RA-ILD, and is often found in SSc-ILD, as well. The prognosis of RA-ILD is known to be poor in patients with a UIP pattern compared to those without UIP $^{60}$.

The radiologic pattern of ILD in CTD-ILD patients dif-
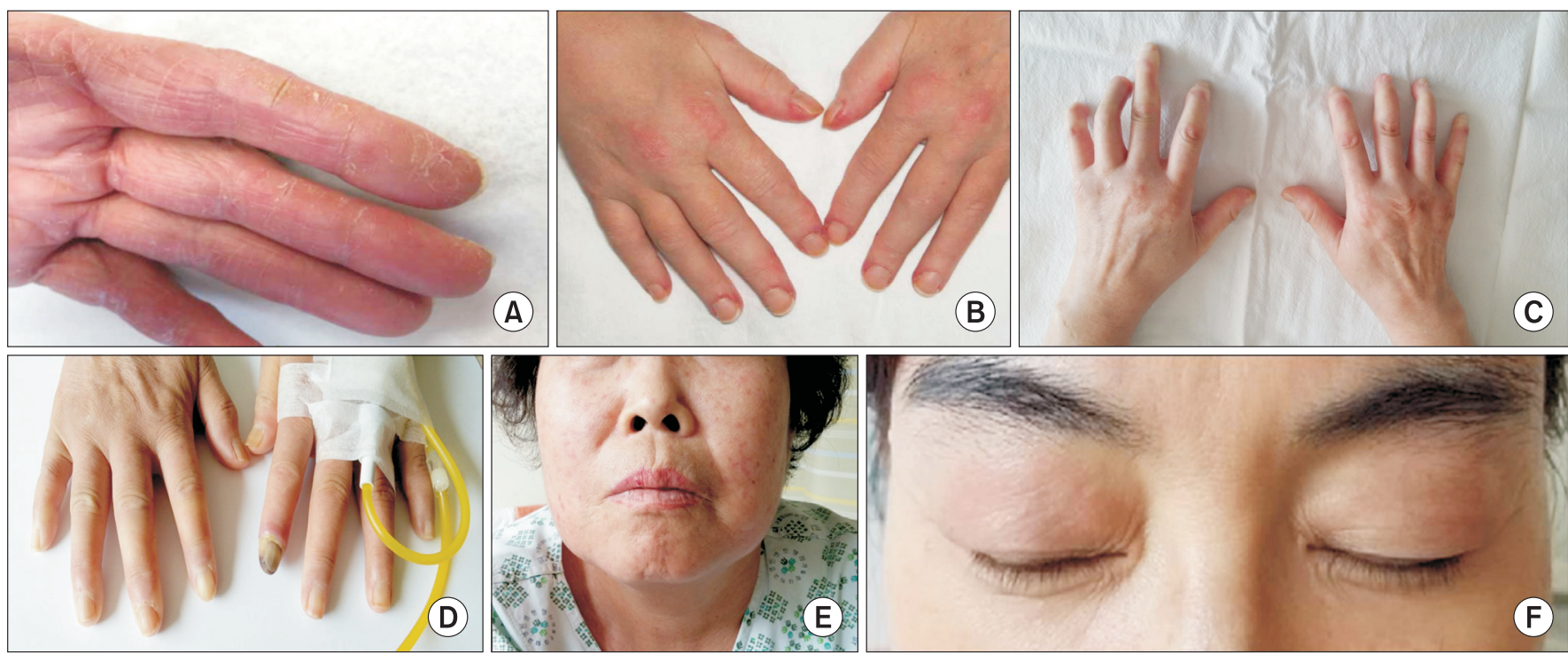

F

Figure 1. (A) Mechanic's hand, cracking and fissuring along the sides of the digits and palm. (B) Gottron's papules, red and scaly papules that erupt on the metacarpophalangeal joints. (C) Sclerodactyly, fixed fingers in a semi-flexed position with tightened and wax like skin. (D) Digital ulceration, an ulceration on the tip of index finger. (E) Telangiectasias, multiple dilated facial small vessels. (F) Heliotrope rash, violaceous erythema on the upper eyelids (The patient provided verbal consent for the picture).
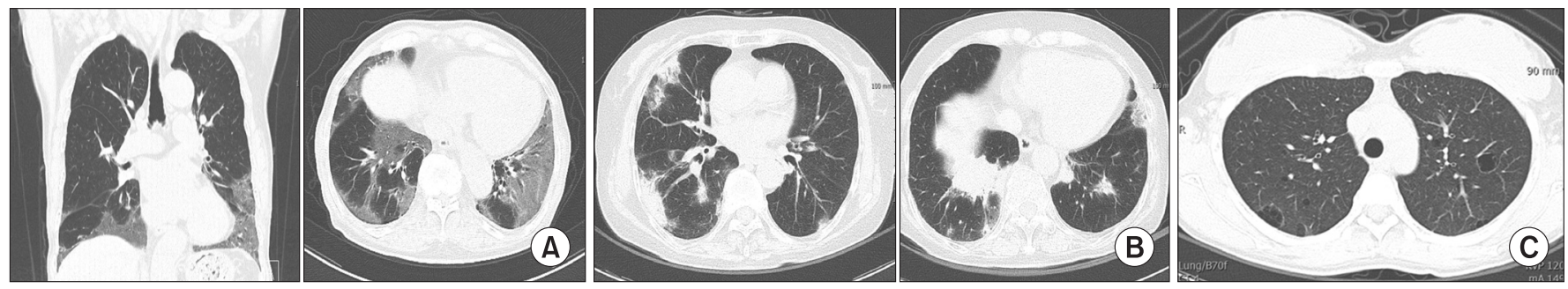

Figure 2. (A) Radiologic pattern of non-specific interstitial pneumonia in a patient with systemic sclerosis. High resolution computed tomography (HRCT) image shows bilateral subpleural and basal predominant fine reticular pattern and ground-glass opacity. (B) Radiologic pattern of organizing pneumonia in a patient with dermatomyositis. HRCT image shows multiple peripheral patch consolidations. (C) Radiologic pattern of lymphocytic interstitial pneumonia in a patient with Sjögren's syndrome. HRCT image shows multifocal variable-sized, thinwalled, cystic lesions on both lungs. 
fers according to CTD type. In RA, UIP is the most common (50\%-60\%); in SSc, NSIP is the most common radiologic finding (80\%-90\%), although UIP is also found in as many as $10 \%-20 \%$; in MCTD, NSIP is the most common; and, in PM and DM, NSIP, OP, UIP, and diffuse alveolar damage may be found ${ }^{65}$.

\section{Surgical lung biopsy}

It is still controversial whether surgical lung biopsy should be performed to confirm the diagnosis when CTD-ILD is suspected. The prognosis may differ depending on the pathological finding (UIP vs. others), and with biopsy, differential diagnoses of other diseases as well as ILD are possible. But, complications may occur following surgical lung biopsy, and thus the decision should be made by considering the pros and cons. In some patients, BAL is an alternative to biopsy, and using this procedure, infection can be excluded and the number

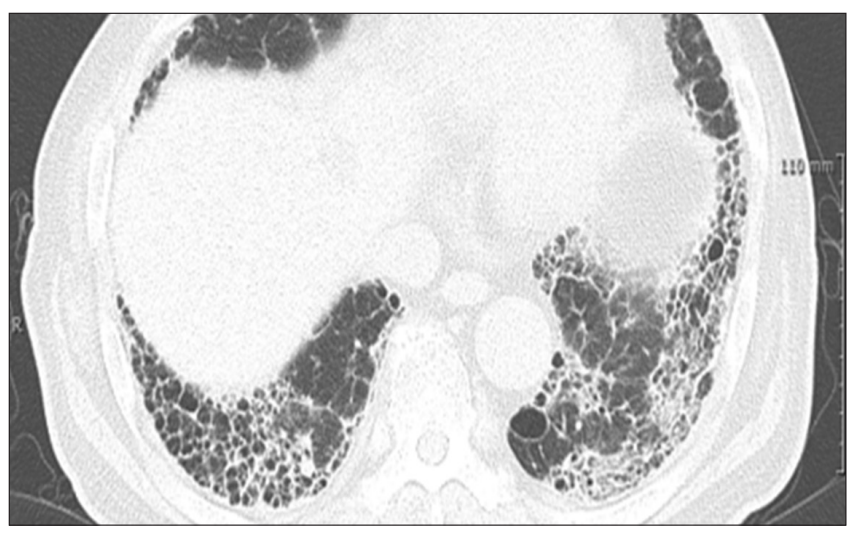

Figure 3. Radiologic pattern of usual interstitial pneumonia in a patient with rheumatoid-arthritis. High resolution computed tomography image shows bilateral subpleural honeycombing and reticular opacity with traction bronchiectasis. of cells is estimated ${ }^{65}$.

Because a specific pathology does not exist in CTD-ILD, IIP and CTD-ILD cannot be completely differentiated based on pathological findings alone. However, because the proportion of NSIP is high in CTD-ILD, the presence or absence of underlying CTD should be looked for if NSIP is found on pathological analysis ${ }^{28,72-78}$.

In addition, among those with CTD-ILD with a UIP pattern there were more germinal centers, lymphoid hyperplasia, plasma cells, and fewer fibroblastic foci and honeycombing, compared with cases of IIP with UIP. If the aforementioned features are found in conjunction with UIP, the presence or absence of CTD should be examined, because the co-occurrence of lymphocytic or follicular bronchiolitis is common (Figure 4) 79-83. $^{79}$.

\section{Autoantibodies}

When a patient is diagnosed with ILD, autoantibody testing should be performed to determine the likelihood of CTD-ILD. As shown in Table 2, cases exist in which an autoantibody is found but the clinical features do not correspond to the diagnosis of CTD or do not meet specific CTD diagnostic criteria. However, since such patients may present clinical features of CTD later, continuous follow-up is required and consultation with a rheumatologist for the symptoms is necessary ${ }^{64,65}$.

\section{Treatment of CTD-ILD}

\section{Acute presentations of CTD-ILD}

Acute presentation of CTD-ILD manifests itself in de novo acute interstitial pneumonia or an acute exacerbation of underlying CTD $^{65}$. The treatment approach for acute exacerbation of CTD-ILD has not yet been established, but conventionally, it is treated using intravenous methylprednisolone $(1 \mathrm{~g} /$
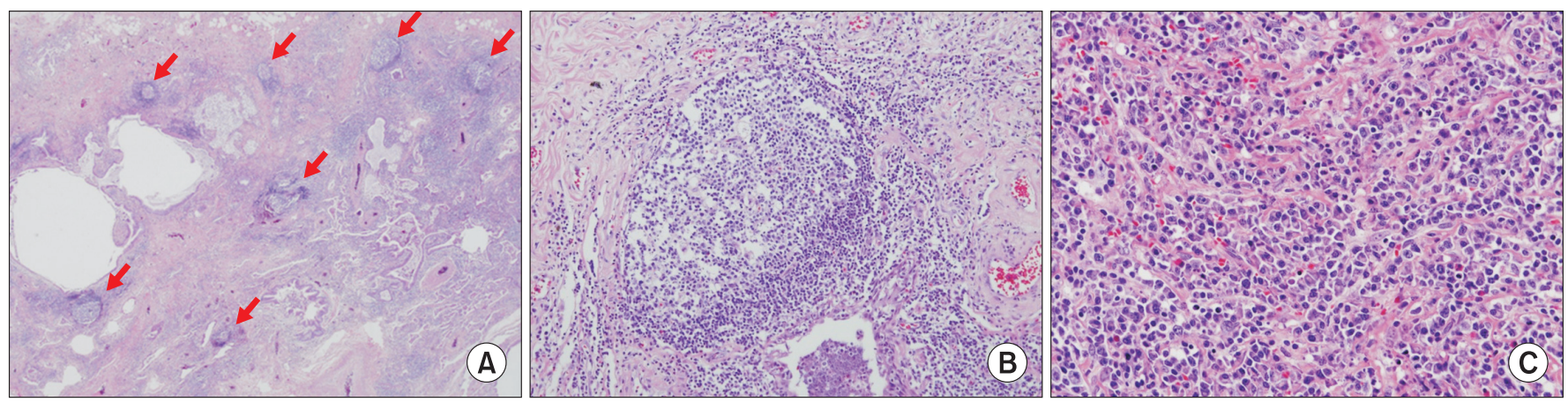

Figure 4. Histopathology of the lung in a patient with interstitial pneumonia with autoimmune features. (A) Usual interstitial with lymphoid follicles $(\times 10)$. (B) Lymphoid bronchiolitis $(\times 100)$. (C) lymphoplasmacytoid cell infiltrates $(\times 200)$. Hematoxylin eosin saffron. Courtesy of Prof. Shim HS, Yonsei University. 
Table 2. Types and significance of autoantibodies ${ }^{65}$

\begin{tabular}{|ll|}
\hline \multicolumn{1}{|c|}{ Test } & \multicolumn{1}{c|}{ Interpretation } \\
\hline Antinuclear antibody & It is nonspecific, but the likelihood of CTD is high if the titer is high \\
\hline Rheumatoid factor & It may increase in RA, but is nonspecific in other types of CTD \\
\hline Scl-70 & Associated with SSc \\
\hline RNP & Associated with MCTD \\
\hline SSA, SSB & Associated with Sjögren's syndrome \\
\hline Anti-CCP & Associated with RA \\
\hline ANCA & It may be observed in pure ILD, though rare \\
\hline Jo-1 & Myositis-specific antibody \\
\hline Tests associated with other types of myositis & \\
\hline Antisynthetase & PL-7, PL-12, EJ, and OJ antibodies \\
MDA-5 & all associated with ILD \\
\hline PMScl & Associated with invasive Gottron's papules and severe ILD \\
\hline Ro-52 & Associated with polymyostis co-occurring with sclerosis \\
CPK, Aldolase & Associated with severe ILD \\
\hline
\end{tabular}

CTD: connective tissue disease; RA: rheumatoid arthritis; SSc: systemic sclerosis; RNP: ribonucleoprotein; MCTD: mixed connective tissue disease; CCP: cyclic citrullinated peptide; ANCA: antineutrophil cytoplasmic antibody; ILD: interstitial lung disease.

Table 3. Summary of acute presentation of CTD-ILD

\begin{tabular}{|ll|}
\hline Causative factor & Infection \\
& Pulmonary embolism \\
& Coronary artery disease \\
& De novo cardiac arrhythmia \\
& Pulmonary edema \\
& Pneumothorax \\
& Surgery, especially lung biopsy \\
& Pulmonary hypertension associated with ILD \\
& Air pollution, especially exposure to ozone and nitrogen dioxide \\
Bisk factor & Broad spectrum antibiotics to treat typical and atypical bacterial-infection \\
& Test and treatment of Pneumocystis jirovecii and other fungal infection based on immunosuppression \\
Treatment & Discontinue drug treatment if drug toxicity is suspected \\
& Methylprednisolone pulse therapy (daily infusion of $1 \mathrm{~g}$ for 3 days) \\
\hline
\end{tabular}

CTD-ILD: connective tissue disease associated with interstitial lung disease.

day intravenously for 3 days) followed by oral prednisolone ( $1 \mathrm{mg} / \mathrm{kg} /$ day). Cyclosporine (500-750 $\mathrm{mg} / \mathrm{m}^{2}$ intravenously) and cyclophosphamide (CYC) $(2-3 \mathrm{mg} / \mathrm{kg} /$ day) may additionally be administered (Table 3 ). Despite immunosuppressive therapy, patients presenting an acute exacerbation often need a ventilator and the mortality rate is high $(83.3 \%)^{65,84,85}$.

\section{Chronic presentations of ILD}

The fundamental treatment of CTD-ILD is to tackle the primary cause of CTD. Evidence regarding treatment effect in
CTD-ILD is lacking, because comparison group studies have not been conducted with the exception of SSc-ILD. Consensus has not yet formed regarding treatment initiation for CTDILD, but conventionally, a steroid or immunosuppressive drug is administered in patients in whom clinical features are severe, symptoms have recently started to progress, or the duration of systemic disease has been short ${ }^{86}$. Lung transplantation may be considered if the patient does not respond to drug therapy and ILD worsens. 


\section{1) Initial treatment of CTD-ILD}

For the initial treatment of CTD-ILD, steroids are commonly used, but the recommendation as to which steroid is appropriate is undecided. The dose, route of administration, treatment duration, and dose tapering vary according to individual patients' clinical picture and the clinician's impression (Table 4$)^{65}$. As the most common ILD form in IIM-ILD patients is OP, prednisolone $1 \mathrm{mg} / \mathrm{kg} /$ day is often used, i.e., the dose at which clinicians are relatively experienced in the treatment of cryptogenic organizing pneumonia (COP). However, treatment response to the therapy is reported to be low in the all forms of IIM-ILD except $\mathrm{COP}^{87}$.

Azathioprine ( $1-2 \mathrm{mg} / \mathrm{kg} /$ day) is often administered as combination therapy with a steroid to treat CTD-ILD, but evidence regarding monotherapy is insufficient ${ }^{88}$. A retrospective survival analysis conducted on 192 IIM-ILD patients showed lower mortality in the group administered with azathioprine (hazard ratio, $0.35 ; 95 \%$ confidence interval, $0.16-0.74$; $\mathrm{p}=0.0064)^{47}$, but there is no evidence of an improvement in the survival rate in other forms of CTD-ILD.

CYC is the only immunosuppressive investigated in a randomized controlled trial. In SSc-ILD, FVC was improved after 1-year treatment in oral CYC ( $2 \mathrm{mg} / \mathrm{kg} /$ day $)$ group compared with the control group ${ }^{89}$. Evidence on pulmonary function improvement is lacking in other types of CTD-ILD aside from SSc-ILD.

In a study with 125 patient cases with SSc-ILD, IIM-ILD, and RA-ILD, mycophenolate mofetil (MMF; 1.0-1.5 g bid) showed a reduction in the required dose of steroid and an improvement in $\mathrm{FVC}^{90}$. In addition, a recent randomized controlled trial with SSc-ILD patients demonstrated that the effect of MMF was similar to that of $\mathrm{CYC}^{91}$.

A retrospective study in IIM-ILD patients found that compared to the groups administered with CYC or cyclosporine in combination with a steroid, the group in whom tacrolimus was added had more favorable event-free survival ${ }^{92}$. The typical dose of tacrolimus is $1-3 \mathrm{mg} / \mathrm{day}^{65}$.

Currently, a randomized controlled trial with rapidly progressive CTD-ILD (including SSC-ILD, IIM-ILD, and MCTDILD) is under way to compare the effects of CYC and rituximab

Table 4. Initial treatment of CTD-ILD ${ }^{85}$

\begin{tabular}{|ll|}
\hline \multicolumn{1}{|c|}{ Classification } & $\begin{array}{c}\text { Most types of CTD-ILD } \\
\text { (with an exception of SSc-ILD) }\end{array}$ \\
\hline Dose & $\begin{array}{l}\text { Initial dose: prednisolone } 0.5-1 \mathrm{mg} / \mathrm{kg} \\
\text { Maintenance dose: tapered to } \\
\text { prednisolone } 10 \mathrm{mg} / \text { day or lower }\end{array}$ \\
Steroid tapering guidance & $\begin{array}{c}\text { Oral or intravenous } \\
\text { cyclophosphamide or concurrent } \\
\text { use of oral azathioprine }\end{array}$ \\
\hline
\end{tabular}

CTD-ILD: connective tissue disease associated interstitial lung disease (ILD); SSc-ILD: systemic sclerosis associated ILD. with FVC improvement as the primary endpoint ${ }^{93}$.

Table 5 summarizes treatment options for each CTD-ILD.

\section{2) Treatment of SSc-ILD}

(1) PICO for treatment of patients with SSc-ILD: In SScILD, is CYC more effective compared with placebo?

(2) Summary of recommendations for the treatment of patients with SSc-ILD: We suggest that the use of CYC may be considered in consultation with an expert, in some SScILD patients experiencing dyspnea and reduced pulmonary function (weak recommendation, level of evidence; low).

FVC, total lung capacity (TLC), dyspnea, and quality of life index improved in the patient group administered with oral CYC over 1 year compared to placebo. A 1-year follow up after treatment termination showed that the improvement in dyspnea was maintained, but other indices returned to the levels prior to drug administration. Thus, evidence for long-term effectiveness of CYC is not sufficient, but it improved dyspnea and had a short-term effect in improving pulmonary function.

The effect of CYC in SSc-ILD patients has been reported in a considerable number of studies, but most of the studies were retrospective. Even the prospective studies tend to lack a comparison group or be observational. The authors conducted a systematic literature review on randomized placebocontrolled studies to investigate whether CYC has a positive effect on various SSc-ILD related indices such as the rate of pulmonary function decline, severity of dyspnea, quality of life, and functional ability. But the authors could not conduct meta-analysis because there was only one randomized placebo-controlled trial on CYC, i.e., Tashkin et al's Scleroderma Lung Study (SLS) ${ }^{89}$ published in NEngl J Med in 2006.

In SLS, 158 symptomatic SSc-ILD patients in whom disease activity was confirmed on either BAL or chest HRCT were randomly assigned to one of two groups, a group treated with CYC $(2 \mathrm{mg} / \mathrm{kg} / \mathrm{day})$ for a year and a placebo group. During the study period, patients could be treated with prednisolone up

Table 5. Summary of treatment of CTD-ILD

\begin{tabular}{|c|c|}
\hline & Treatment \\
\hline \multirow[t]{2}{*}{ SSc-ILD } & Cyclophosphamide, MMF \\
\hline & Rituximab can be used \\
\hline RA-ILD & Steroid, MMF, and rituximab can be considered \\
\hline DM/PM-ILD & $\begin{array}{l}\text { Steroid, MMF, azathioprine, tacrolimus, and } \\
\text { rituximab can be considered }\end{array}$ \\
\hline \multirow[t]{2}{*}{ Other CTD-ILD } & Steroid \\
\hline & $\begin{array}{l}\text { Cyclophosphamide or azathioprine according } \\
\text { to the steroid tapering }\end{array}$ \\
\hline
\end{tabular}

CTD-ILD: connective tissue disease associated interstitial disease (ILD); SSc-ILD: systemic sclerosis associated ILD; MMF: mycophenolate mofetil; RA-ILD: rheumatoid arthritis associated ILD; DM/PMILD: dermatomyositis/polymyositis associated ILD. 
to $10 \mathrm{mg} /$ day. If an FVC reduction of $15 \%$ versus the baseline continued over 1 month from month 3 after treatment initiation, it was considered as treatment failure and the patient was unblinded and treated with CYC. The primary endpoint of the study was the FVC (expressed as a percentage of the predicted value) at 1 year after adjusting for baseline values and treatment group. Secondary endpoints were TLC, change in DLCO, disability index of health assessment questionnaire (HAQ), SF-36, transitional dyspnea index (TDI), and skin thickness score. Between-group difference in FVC change after 1 year of CYC administration was $2.53 \%$ (95\% confidence interval, 0.28-4.79; $\mathrm{p}<0.03$ ), indicating that treatment with CYC significantly slowed down the rate of FVC reduction. Of the secondary endpoints, TLC, HAQ, TDI, and skin thickness score were significantly improved in the CYC group in comparison to the placebo group.

Side effects of CYC that occurred during the study were hematuria (hemorrhagic cystitis), leukopenia, neutropenia, anemia, pneumonia, etc. ${ }^{89,94}$. Therefore, it is recommended to regularly perform blood test and use mesna for the prevention of hemorrhagic cystitis, in patients treated with CYC. Long-term use of the drug is not recommended because of increased risk for bladder cancer and other malignant diseases.

After the completion of this SLS study, the researchers followed up the patients for an additional 1 year without administering a drug in order to investigate the duration of drug effect $^{94}$. During the additional 1-year follow-up, if treatment failure (an FVC reduction over 15\% compared to the baseline) occurred in either group, the patient was treated with CYC or an immunosuppressive according to the clinician's decision. During the 1-year follow-up, between-group differences in FVC and TLC were significant for the first 6 months, that is, the drug effect was maintained for a total of 18 months from the start of the study. But group difference disappeared by month 12 after treatment termination (that is, 24 months after the start of the study). An additional analysis showed a larger drug effect in patients with FVC less than $70 \%$. On the other hand, the improvement of TDI (an index of dyspnea) was maintained up to month 12 after treatment termination ${ }^{94}$.

In summary, a year-long treatment with CYC administration improved pulmonary function, dyspnea, and quality of life and the effects were maintained up to 6 months after treatment termination. One year after treatment termination, two groups still showed a significant difference in dyspnea but not in FVC or TLC. Based on the improvement of dyspnea that was maintained as long as 1 year after treatment termination and a short-term improvement of pulmonary function, CYC may be useful in some SSc-ILD patients. Thus, in SSc-ILD patients experiencing dyspnea and reduced FVC, a short-term use of CYC may be considered in consultation with an expert.

Regarding drugs other than CYC, first, a study showed that steroid therapy $(0.5-1 \mathrm{~kg} / \mathrm{kg}$ of prednisolone) could be expected to slow down pulmonary function decline ${ }^{95}$, though the effect of steroid in treatment of SSc-ILD is controversial. High dose steroid is not recommended because renal crisis can rapidly develop if the daily dose of prednisolone is over 10 $\mathrm{mg}^{86}$.

MMF has been known to suppress lymphoproliferation and to have an antifibrotic effect. A recently presented randomized comparison group study, Scleroderma Lung Study II (SLS II), compared a patient group administered with MMF (1,500 $\mathrm{mg}$ bid) for 24 months and a patient group administered with CYC ( $2 \mathrm{mg} / \mathrm{kg} /$ day) for 12 months. There was little difference in the speed of FVC reduction between the MMF group and the CYC group, and the counts of leucocytes and platelets in the MMF group did not decrease as much as in the CYC group $^{91}$. Based on the findings, MMF may be considered as initial and maintenance therapies in the treatment of SSc-ILD.

Lately, hematopoietic stem cell transplantation (HSCT) has been attempted in SSc-ILD patients. A randomized controlled trial that compared the effects of HSCT and CYC reported that HSCT helped improve long-term event-free survival and overall survival, but recurrence rate was higher ${ }^{96}$. Accordingly, HSCT may be considered in cases in which patients did not respond to immunosuppressive therapy or the disease had progressed.

In an open-label randomized controlled trial that investigated rituximab (a B cell depletion therapy) in SSc-ILD, the drug showed an effect of increasing FVC and DLCO 1 year after commencement of therapy ${ }^{97}$. However, the study included only 12 patients in the sample, which is very small. So far, there is not enough evidence regarding rituximab, and largescale randomized comparison group research is needed ${ }^{98}$. As for now, it is believed that patients not responding to the currently available immunosuppressives may be tested on rituximab in a limited manner.

Lung transplantation is the only treatment available to prolong survival of SSc-ILD patients not responding to drug therapy. To improve the prognosis following lung transplantation, suitable patient selection is important. A recent study has proposed the following as lung transplantation exclusion criteria: uncontrolled active inflammatory myopathies, active digital ulcerations, severe SSc associated gastrointestinal disease, cardiac arrhythmia, unstable renal function over the last 3 months, and high risk of SSc associated renal crisis ${ }^{99}$. However, standardized criteria have not yet been established and further research is warranted.

\section{3) Treatment of RA-ILD}

(1) PICO for treatment of patients with RA-ILD: In RAILD, do steroids and immunosuppressants (MMF, rituximab) slow the worsening of FVC compared with placebo?

(2) Summary of recommendations for the treatment of patients with RA-ILD: We suggest that, in clinically severe cases, the use of the steroid, MMF, and rituximab may be considered in consultation with an expert (recommendation; 
expert opinion, level of evidence; low).

If RA-ILD deteriorates despite administration of disease modifying antirheumatic drugs (DMARDs: RA treatment) and tumor necrosis factor inhibitors, conventionally high-dose prednisolone therapy is administered ${ }^{100}$. But, the evidence for the effectiveness and safety of drug therapy is weak ${ }^{100}$ and comparison group studies have never been conducted to evaluate drugs in RA-ILD patients.

The authors attempted a systematic literature review and meta-analysis on the effects of steroid and immunosuppressive therapy (MMF and rituximab) in RA-ILD, but could not perform comparative analysis because no study compared steroid or immunosuppressive therapy to placebo. Below are the findings reported in a few single-group studies that used steroid or immunosuppressive therapy such as MMF and rituximab in RA-ILD patients. In a retrospective cohort consisting of 40 RA-ILD patients, baseline FVC improved when prednisolone $(1 \mathrm{mg} / \mathrm{kg} /$ day $)$ was administered for 6 weeks and then tapered down to $10 \mathrm{mg} /$ day while a DMARD was administered during a follow-up over 6-8 months ${ }^{101}$. A retrospective single-group study was conducted with 18 CTD-ILD patients including some with RA-ILD and it was found that pulmonary function stabilized and prednisolone maintenance dose decreased during a median of 2.5-year follow-up after treatment with $\mathrm{MMF}^{90}$. A prospective cohort study ${ }^{102}$ and two retrospective studies ${ }^{103,104}$ with RA-ILD patients reported that rituximab stabilized pulmonary function. Also, it was reported that when rituximab (1,000 $\mathrm{mg}$ at day 1,15 , and again at weeks 24 and 26, with methotrexate) was used concomitantly with methotrexate, FVC was maintained in six out of seven RA-ILD patients after 48 weeks ${ }^{102}$. Also, some case studies reported that azathioprine ${ }^{105}$, abatacept ${ }^{106}$, tocilizumab ${ }^{107}$, and infliximab ${ }^{108}$ each stabilized pulmonary function in RAILD patients.

There is no clear consensus as to when to initiate treatment with the drugs mentioned above. Since no other drug has so far been demonstrated to be effective in RA-ILD, the use of steroids, MMF, or rituximab may be considered for clinically severe cases, in consultation with a specialist.

\section{Prognosis of CTD-ILD}

The prognosis of CTD-ILD patients varies according to the type of causative CTD. RA-ILD comprises 10\%-20\% of deaths among RA patients ${ }^{109}$, and $10 \%$ of deaths among all ILD patients $^{7-9}$. In SSc-ILD, it is reported that 10-year survival following diagnosis lies in the range $29 \%-69 \%$. and that in $45 \%-55 \%$ of the patients, pulmonary function deteriorates within the first 3 years, and in $16 \%$ severe restrictive pulmonary disease develops ${ }^{1}$. In Sjögren's syndrome the 5-year survival is reported to be $84 \%^{110}$.

If ILD progresses in spite of immunosuppressive therapy, lung transplantation may be considered. The prognosis of CTD-ILD after lung transplantation is reported to be not very different from that of lung transplantation in IIP patients.

\section{Authors' Contributions}

Conceptualization: Choi SM, Lee HK. Formal analysis: Koo SM, Km SY, Choi SM, Lee HK. Data curation: Koo SM, Choi SM. Writing - original draft preparation: Koo SM, Kim SY. Writing - review and editing: Choi SM, Lee HK. Approval of final manuscript: all authors.

\section{Conflicts of Interest}

No potential conflict of interest relevant to this article was reported.

\section{Funding}

No funding to declare.

\section{References}

1. Steen VD, Conte C, Owens GR, Medsger TA Jr. Severe restrictive lung disease in systemic sclerosis. Arthritis Rheum 1994;37:1283-9.

2. Fewins HE, McGowan I, Whitehouse GH, Williams J, Mallya R. High definition computed tomography in rheumatoid arthritis associated pulmonary disease. Br J Rheumatol 1991;30:214-6.

3. Gabbay E, Tarala R, Will R, Carroll G, Adler B, Cameron D, et al. Interstitial lung disease in recent onset rheumatoid arthritis. Am J Respir Crit Care Med 1997;156(2 Pt 1):528-35.

4. McDonagh J, Greaves M, Wright AR, Heycock C, Owen JP, Kelly C. High resolution computed tomography of the lungs in patients with rheumatoid arthritis and interstitial lung disease. Br J Rheumatol 1994;33:118-22.

5. Cortet B, Perez T, Roux N, Flipo RM, Duquesnoy B, Delcambre B, et al. Pulmonary function tests and high resolution computed tomography of the lungs in patients with rheumatoid arthritis. Ann Rheum Dis 1997;56:596-600.

6. Winstone TA, Assayag D, Wilcox PG, Dunne JV, Hague CJ, Leipsic J, et al. Predictors of mortality and progression in scleroderma-associated interstitial lung disease: a systematic review. Chest 2014;146:422-36.

7. Cavagna L, Monti S, Grosso V, Boffini N, Scorletti E, Crepaldi $\mathrm{G}$, et al. The multifaceted aspects of interstitial lung disease in rheumatoid arthritis. Biomed Res Int 2013;2013:759760.

8. de Lauretis A, Veeraraghavan S, Renzoni E. Review series: 
aspects of interstitial lung disease: connective tissue disease-associated interstitial lung disease: how does it differ from IPF? How should the clinical approach differ? Chron Respir Dis 2011;8:53-82.

9. Bongartz T, Nannini C, Medina-Velasquez YF, Achenbach SJ, Crowson CS, Ryu JH, et al. Incidence and mortality of interstitial lung disease in rheumatoid arthritis: a populationbased study. Arthritis Rheum 2010;62:1583-91.

10. Assayag D, Lubin M, Lee JS, King TE, Collard HR, Ryerson CJ. Predictors of mortality in rheumatoid arthritis-related interstitial lung disease. Respirology 2014;19:493-500.

11. Saag KG, Kolluri S, Koehnke RK, Georgou TA, Rachow JW, Hunninghake GW, et al. Rheumatoid arthritis lung disease: determinants of radiographic and physiologic abnormalities. Arthritis Rheum 1996;39:1711-9.

12. Turesson C. Extra-articular rheumatoid arthritis. Curr Opin Rheumatol 2013;25:360-6.

13. Doyle TJ, Lee JS, Dellaripa PF, Lederer JA, Matteson EL, Fischer A, et al. A roadmap to promote clinical and translational research in rheumatoid arthritis-associated interstitial lung disease. Chest 2014;145:454-63.

14. Kelly CA, Saravanan V, Nisar M, Arthanari S, Woodhead FA, Price-Forbes AN, et al. Rheumatoid arthritis-related interstitial lung disease: associations, prognostic factors and physiological and radiological characteristics: a large multicentre UK study. Rheumatology (Oxford) 2014;53:1676-82.

15. Ytterberg AJ, Joshua V, Reynisdottir G, Tarasova NK, Rutishauser D, Ossipova E, et al. Shared immunological targets in the lungs and joints of patients with rheumatoid arthritis: identification and validation. Ann Rheum Dis 2015;74:17727.

16. Aubart F, Crestani B, Nicaise-Roland P, Tubach F, Bollet C, Dawidowicz K, et al. High levels of anti-cyclic citrullinated peptide autoantibodies are associated with co-occurrence of pulmonary diseases with rheumatoid arthritis. J Rheumatol 2011;38:979-82.

17. Luukkainen R, Saltyshev M, Pakkasela R, Nordqvist E, Huhtala H, Hakala M. Relationship of rheumatoid factor to lung diffusion capacity in smoking and non-smoking patients with rheumatoid arthritis. Scand J Rheumatol 1995;24:119-20.

18. Tuomi T, Heliovaara M, Palosuo T, Aho K. Smoking, lung function, and rheumatoid factors. Ann Rheum Dis 1990;49:753-6.

19. Lamblin C, Bergoin C, Saelens T, Wallaert B. Interstitial lung diseases in collagen vascular diseases. Eur Respir J Suppl 2001;32:69s-80s.

20. Desai SR, Veeraraghavan S, Hansell DM, Nikolakopolou A, Goh NS, Nicholson AG, et al. CT features of lung disease in patients with systemic sclerosis: comparison with idiopathic pulmonary fibrosis and nonspecific interstitial pneumonia. Radiology 2004;232:560-7.

21. Walker UA, Tyndall A, Czirjak L, Denton C, Farge-Bancel D,
Kowal-Bielecka O, et al. Clinical risk assessment of organ manifestations in systemic sclerosis: a report from the EULAR Scleroderma Trials And Research group database. Ann Rheum Dis 2007;66:754-63.

22. Zhang XJ, Bonner A, Hudson M; Canadian Scleroderma Research Group, Baron M, Pope J. Association of gastroesophageal factors and worsening of forced vital capacity in systemic sclerosis. J Rheumatol 2013;40:850-8.

23. Wells AU, Margaritopoulos GA, Antoniou KM, Denton C. Interstitial lung disease in systemic sclerosis. Semin Respir Crit Care Med 2014;35:213-21.

24. Briggs DC, Vaughan RW, Welsh KI, Myers A, duBois RM, Black CM. Immunogenetic prediction of pulmonary fibrosis in systemic sclerosis. Lancet 1991;338:661-2.

25. Hu PQ, Fertig N, Medsger TA Jr, Wright TM. Correlation of serum anti-DNA topoisomerase I antibody levels with disease severity and activity in systemic sclerosis. Arthritis Rheum 2003;48:1363-73.

26. Raghu G, Collard HR, Egan JJ, Martinez FJ, Behr J, Brown KK, et al. An official ATS/ERS/JRS/ALAT statement: idiopathic pulmonary fibrosis: evidence-based guidelines for diagnosis and management. Am J Respir Crit Care Med 2011;183:788824.

27. Solomon JJ, Olson AL, Fischer A, Bull T, Brown KK, Raghu G. Scleroderma lung disease. Eur Respir Rev 2013;22:6-19.

28. Bouros D, Wells AU, Nicholson AG, Colby TV, Polychronopoulos V, Pantelidis P, et al. Histopathologic subsets of fibrosing alveolitis in patients with systemic sclerosis and their relationship to outcome. Am J Respir Crit Care Med 2002;165:1581-6.

29. Moore OA, Goh N, Corte T, Rouse H, Hennessy O, Thakkar V, et al. Extent of disease on high-resolution computed tomography lung is a predictor of decline and mortality in systemic sclerosis-related interstitial lung disease. Rheumatology (Oxford) 2013;52:155-60.

30. Steen VD, Medsger TA. Changes in causes of death in systemic sclerosis, 1972-2002. Ann Rheum Dis 2007;66:940-4.

31. Dellaripa PF, Fischer A, Flaherty KR. Pulmonary manifestations of rheumatic disease: a comprehensive guide. New York: Springer; 2014.

32. Palm O, Garen T, Berge Enger T, Jensen JL, Lund MB, Aalokken TM, et al. Clinical pulmonary involvement in primary Sjogren's syndrome: prevalence, quality of life and mortality: a retrospective study based on registry data. Rheumatology (Oxford) 2013;52:173-9.

33. Ramos-Casals M, Solans R, Rosas J, Camps MT, Gil A, Del Pino-Montes J, et al. Primary Sjogren syndrome in Spain: clinical and immunologic expression in 1010 patients. Medicine (Baltimore) 2008;87:210-9.

34. Yazisiz V, Arslan G, Ozbudak IH, Turker S, Erbasan F, Avci $\mathrm{AB}$, et al. Lung involvement in patients with primary Sjogren's syndrome: what are the predictors? Rheumatol Int 2010;30:1317-24. 
35. Uffmann M, Kiener HP, Bankier AA, Baldt MM, Zontsich T, Herold CJ. Lung manifestation in asymptomatic patients with primary Sjogren syndrome: assessment with high resolution CT and pulmonary function tests. J Thorac Imaging 2001;16:282-9.

36. Cain HC, Noble PW, Matthay RA. Pulmonary manifestations of Sjogren's syndrome. Clin Chest Med 1998;19:68799.

37. Parambil JG, Myers JL, Lindell RM, Matteson EL, Ryu JH. Interstitial lung disease in primary Sjogren syndrome. Chest 2006;130:1489-95.

38. Sirianni FE, Milaninezhad A, Chu FS, Walker DC. Alteration of fibroblast architecture and loss of Basal lamina apertures in human emphysematous lung. Am J Respir Crit Care Med 2006;173:632-8.

39. Sharp GC, Irvin WS, Tan EM, Gould RG, Holman HR. Mixed connective tissue disease: an apparently distinct rheumatic disease syndrome associated with a specific antibody to an extractable nuclear antigen (ENA). Am J Med 1972;52:14859.

40. Tani C, Carli L, Vagnani S, Talarico R, Baldini C, Mosca M, et al. The diagnosis and classification of mixed connective tissue disease. J Autoimmun 2014;48-49:46-9.

41. Gunnarsson R, Aalokken TM, Molberg O, Lund MB, Mynarek GK, Lexberg AS, et al. Prevalence and severity of interstitial lung disease in mixed connective tissue disease: a nationwide, cross-sectional study. Ann Rheum Dis 2012;71:1966-72.

42. Gunnarsson R, El-Hage F, Aalokken TM, Reiseter S, Lund MB, Garen T, et al. Associations between anti-Ro52 antibodies and lung fibrosis in mixed connective tissue disease. Rheumatology (Oxford) 2016;55:103-8.

43. Fathi M, Dastmalchi M, Rasmussen E, Lundberg IE, Tornling G. Interstitial lung disease, a common manifestation of newly diagnosed polymyositis and dermatomyositis. Ann Rheum Dis 2004;63:297-301.

44. Lee CS, Chen TL, Tzen CY, Lin FJ, Peng MJ, Wu CL, et al. Idiopathic inflammatory myopathy with diffuse alveolar damage. Clin Rheumatol 2002;21:391-6.

45. Chen IJ, Jan Wu YJ, Lin CW, Fan KW, Luo SF, Ho HH, et al. Interstitial lung disease in polymyositis and dermatomyositis. Clin Rheumatol 2009;28:639-46.

46. Hayashi S, Tanaka M, Kobayashi H, Nakazono T, Satoh T, Fukuno Y, et al. High-resolution computed tomography characterization of interstitial lung diseases in polymyositis/ dermatomyositis. J Rheumatol 2008;35:260-9.

47. Yu KH, Wu YJ, Kuo CF, See LC, Shen YM, Chang HC, et al. Survival analysis of patients with dermatomyositis and polymyositis: analysis of 192 Chinese cases. Clin Rheumatol 2011;30:1595-601.

48. Ji SY, Zeng FQ, Guo Q, Tan GZ, Tang HF, Luo YJ, et al. Predictive factors and unfavourable prognostic factors of interstitial lung disease in patients with polymyositis or dermatomyositis: a retrospective study. Chin Med J (Engl) 2010;123:517-22.

49. Matsushita T, Hasegawa M, Fujimoto M, Hamaguchi Y, Komura K, Hirano T, et al. Clinical evaluation of anti-aminoacyl tRNA synthetase antibodies in Japanese patients with dermatomyositis. J Rheumatol 2007;34:1012-8.

50. Yoshifuji H, Fujii T, Kobayashi S, Imura Y, Fujita Y, Kawabata D, et al. Anti-aminoacyl-tRNA synthetase antibodies in clinical course prediction of interstitial lung disease complicated with idiopathic inflammatory myopathies. Autoimmunity 2006;39:233-41.

51. Tillie-Leblond I, Wislez M, Valeyre D, Crestani B, Rabbat A, Israel-Biet D, et al. Interstitial lung disease and anti-Jo-1 antibodies: difference between acute and gradual onset. Thorax 2008;63:53-9.

52. Kono M, Nakamura Y, Enomoto N, Hashimoto D, Fujisawa $\mathrm{T}$, Inui N, et al. Usual interstitial pneumonia preceding collagen vascular disease: a retrospective case control study of patients initially diagnosed with idiopathic pulmonary fibrosis. PLoS One 2014;9:e94775.

53. Solomon J, Swigris JJ, Brown KK. Myositis-related interstitial lung disease and antisynthetase syndrome. J Bras Pneumol 2011;37:100-9.

54. Doyle TJ, Dellaripa PF. Lung manifestations in the rheumatic diseases. Chest 2017;152:1283-95.

55. Mittoo S, Fell CD. Pulmonary manifestations of systemic lupus erythematosus. Semin Respir Crit Care Med 2014;35:249-54.

56. Chua F, Higton AM, Colebatch AN, O'Reilly K, Grubnic S, Vlahos I, et al. Idiopathic inflammatory myositis-associated interstitial lung disease: ethnicity differences and lung function trends in a British cohort. Rheumatology (Oxford) 2012;51:1870-6.

57. Eisenberg H, Dubois EL, Sherwin RP, Balchum OJ. Diffuse interstitial lung disease in systemic lupus erythematosus. Ann Intern Med 1973;79:37-45.

58. ter Borg EJ, Groen H, Horst G, Limburg PC, Wouda AA, Kallenberg CG. Clinical associations of antiribonucleoprotein antibodies in patients with systemic lupus erythematosus. Semin Arthritis Rheum 1990;20:164-73.

59. Ward MM, Polisson RP. A meta-analysis of the clinical manifestations of older-onset systemic lupus erythematosus. Arthritis Rheum 1989;32:1226-32.

60. Perez T, Farre JM, Gosset P, Wallaert B, Duquesnoy B, Voisin $\mathrm{C}$, et al. Subclinical alveolar inflammation in rheumatoid arthritis: superoxide anion, neutrophil chemotactic activity and fibronectin generation by alveolar macrophages. Eur Respir J 1989;2:7-13.

61. Doyle TJ, Hunninghake GM, Rosas IO. Subclinical interstitial lung disease: why you should care. Am J Respir Crit Care Med 2012;185:1147-53.

62. Gochuico BR, Avila NA, Chow CK, Novero LJ, Wu HP, Ren P, et al. Progressive preclinical interstitial lung disease in rheu- 
matoid arthritis. Arch Intern Med 2008;168:159-66.

63. Launay D, Remy-Jardin M, Michon-Pasturel U, Mastora I, Hachulla E, Lambert M, et al. High resolution computed tomography in fibrosing alveolitis associated with systemic sclerosis. J Rheumatol 2006;33:1789-801.

64. Cottin V. Idiopathic interstitial pneumonias with connective tissue diseases features: a review. Respirology 2016;21:24558.

65. Mathai SC, Danoff SK. Management of interstitial lung disease associated with connective tissue disease. BMJ 2016;352:h6819.

66. Cottin V. Significance of connective tissue diseases features in pulmonary fibrosis. Eur Respir Rev 2013;22:273-80.

67. Mosca M, Tani C, Bombardieri S. A case of undifferentiated connective tissue disease: is it a distinct clinical entity? Nat Clin Pract Rheumatol 2008;4:328-32.

68. Kinder BW, Collard HR, Koth L, Daikh DI, Wolters PJ, Elicker B, et al. Idiopathic nonspecific interstitial pneumonia: lung manifestation of undifferentiated connective tissue disease? Am J Respir Crit Care Med 2007;176:691-7.

69. Corte TJ, Copley SJ, Desai SR, Zappala CJ, Hansell DM, Nicholson AG, et al. Significance of connective tissue disease features in idiopathic interstitial pneumonia. Eur Respir J 2012;39:661-8.

70. Nunes H, Schubel K, Piver D, Magois E, Feuillet S, Uzunhan Y, et al. Nonspecific interstitial pneumonia: survival is influenced by the underlying cause. Eur Respir J 2015;45:746-55.

71. Moua T, Zamora Martinez AC, Baqir M, Vassallo R, Limper AH, Ryu JH. Predictors of diagnosis and survival in idiopathic pulmonary fibrosis and connective tissue disease-related usual interstitial pneumonia. Respir Res 2014;15:154.

72. Park JH, Kim DS, Park IN, Jang SJ, Kitaichi M, Nicholson AG, et al. Prognosis of fibrotic interstitial pneumonia: idiopathic versus collagen vascular disease-related subtypes. Am J Respir Crit Care Med 2007;175:705-11.

73. Kim EJ, Elicker BM, Maldonado F, Webb WR, Ryu JH, Van Uden JH, et al. Usual interstitial pneumonia in rheumatoid arthritis-associated interstitial lung disease. Eur Respir J 2010;35:1322-8.

74. Tansey D, Wells AU, Colby TV, Ip S, Nikolakoupolou A, du Bois RM, et al. Variations in histological patterns of interstitial pneumonia between connective tissue disorders and their relationship to prognosis. Histopathology 2004;44:58596.

75. Kim DS. Interstitial lung disease in rheumatoid arthritis: recent advances. Curr Opin Pulm Med 2006;12:346-53.

76. Cottin V, Thivolet-Bejui F, Reynaud-Gaubert M, Cadranel J, Delaval P, Ternamian PJ, et al. Interstitial lung disease in amyopathic dermatomyositis, dermatomyositis and polymyositis. Eur Respir J 2003;22:245-50.

77. Douglas WW, Tazelaar HD, Hartman TE, Hartman RP, Decker PA, Schroeder DR, et al. Polymyositis-dermatomyositis-associated interstitial lung disease. Am J Respir Crit
Care Med 2001;164:1182-5.

78. Cottin V. Pragmatic prognostic approach of rheumatoid arthritis-associated interstitial lung disease. Eur Respir J 2010;35:1206-8.

79. Fischer A, du Bois R. Interstitial lung disease in connective tissue disorders. Lancet 2012;380:689-98.

80. Antin-Ozerkis D, Rubinowitz A, Evans J, Homer RJ, Matthay RA. Interstitial lung disease in the connective tissue diseases. Clin Chest Med 2012;33:123-49.

81. Song JW, Do KH, Kim MY, Jang SJ, Colby TV, Kim DS. Pathologic and radiologic differences between idiopathic and collagen vascular disease-related usual interstitial pneumonia. Chest 2009;136:23-30.

82. Fischer A, West SG, Swigris JJ, Brown KK, du Bois RM. Connective tissue disease-associated interstitial lung disease: a call for clarification. Chest 2010;138:251-6.

83. Devouassoux G, Cottin V, Liote H, Marchand E, Frachon I, Schuller A, et al. Characterisation of severe obliterative bronchiolitis in rheumatoid arthritis. Eur Respir J 2009;33:105361.

84. Suda T, Kaida Y, Nakamura Y, Enomoto N, Fujisawa T, Imokawa S, et al. Acute exacerbation of interstitial pneumonia associated with collagen vascular diseases. Respir Med 2009;103:846-53.

85. Bradley B, Branley HM, Egan JJ, Greaves MS, Hansell DM, Harrison NK, et al. Interstitial lung disease guideline: the British Thoracic Society in collaboration with the Thoracic Society of Australia and New Zealand and the Irish Thoracic Society. Thorax 2008;63 Suppl 5:v1-58.

86. Wallace B, Vummidi D, Khanna D. Management of connective tissue diseases associated interstitial lung disease: a review of the published literature. Curr Opin Rheumatol 2016;28:236-45.

87. Aggarwal R, Oddis CV. Therapeutic advances in myositis Curr Opin Rheumatol 2012;24:635-41.

88. Hoyles RK, Ellis RW, Wellsbury J, Lees B, Newlands P, Goh NS, et al. A multicenter, prospective, randomized, doubleblind, placebo-controlled trial of corticosteroids and intravenous cyclophosphamide followed by oral azathioprine for the treatment of pulmonary fibrosis in scleroderma. Arthritis Rheum 2006;54:3962-70.

89. Tashkin DP, Elashoff R, Clements PJ, Goldin J, Roth MD, Furst DE, et al. Cyclophosphamide versus placebo in scleroderma lung disease. N Engl J Med 2006;354:2655-66.

90. Fischer A, Brown KK, Du Bois RM, Frankel SK, Cosgrove GP, Fernandez-Perez ER, et al. Mycophenolate mofetil improves lung function in connective tissue disease-associated interstitial lung disease. J Rheumatol 2013;40:640-6.

91. Tashkin DP, Roth MD, Clements PJ, Furst DE, Khanna D, Kleerup EC, et al. Mycophenolate mofetil versus oral cyclophosphamide in scleroderma-related interstitial lung disease (SLS II): a randomised controlled, double-blind, parallel group trial. Lancet Respir Med 2016;4:708-19. 
92. Kurita T, Yasuda S, Amengual O, Atsumi T. The efficacy of calcineurin inhibitors for the treatment of interstitial lung disease associated with polymyositis/dermatomyositis. Lupus 2015;24:3-9.

93. Saunders P, Tsipouri V, Keir GJ, Ashby D, Flather MD, Parfrey $\mathrm{H}$, et al. Rituximab versus cyclophosphamide for the treatment of connective tissue disease-associated interstitial lung disease (RECITAL): study protocol for a randomised controlled trial. Trials 2017;18:275.

94. Tashkin DP, Elashoff R, Clements PJ, Roth MD, Furst DE, Silver RM, et al. Effects of 1-year treatment with cyclophosphamide on outcomes at 2 years in scleroderma lung disease. Am J Respir Crit Care Med 2007;176:1026-34.

95. Ando K, Motojima S, Doi T, Nagaoka T, Kaneko N, Aoshima $\mathrm{M}$, et al. Effect of glucocorticoid monotherapy on pulmonary function and survival in Japanese patients with scleroderma-related interstitial lung disease. Respir Investig 2013;51:69-75.

96. Burt RK, Shah SJ, Dill K, Grant T, Gheorghiade M, Schroeder J, et al. Autologous non-myeloablative haemopoietic stemcell transplantation compared with pulse cyclophosphamide once per month for systemic sclerosis (ASSIST): an open-label, randomised phase 2 trial. Lancet 2011;378:498506.

97. Daoussis D, Liossis SN, Tsamandas AC, Kalogeropoulou C, Kazantzi A, Sirinian C, et al. Experience with rituximab in scleroderma: results from a 1-year, proof-of-principle study. Rheumatology (Oxford) 2010;49:271-80.

98. Lam GK, Hummers LK, Woods A, Wigley FM. Efficacy and safety of etanercept in the treatment of scleroderma-associated joint disease. J Rheumatol 2007;34:1636-7.

99. Launay D, Savale L, Berezne A, Le Pavec J, Hachulla E, Mouthon L, et al. Lung and heart-lung transplantation for systemic sclerosis patients: a monocentric experience of 13 patients, review of the literature and position paper of a multidisciplinary Working Group. Presse Med 2014;43(10 Pt 2):e345-63.

100. Assayag D, Lee JS, King TE Jr. Rheumatoid arthritis associated interstitial lung disease: a review. Medicina (B Aires)
2014;74:158-65.

101. Rojas-Serrano J, Gonzalez-Velasquez E, Mejia M, SanchezRodriguez A, Carrillo G. Interstitial lung disease related to rheumatoid arthritis: evolution after treatment. Reumatol Clin 2012;8:68-71.

102. Matteson EL, Bongartz T, Ryu JH, Crowson CS, Hartman TE, Dellaripa PF. Open-label, pilot study of the safety and clinical effects of rituximab in patients with rheumatoid arthritisassociated interstitial pneumonia. Open J Rheumatol Autoimmune Dis 2012;2:53-8.

103. Keir GJ, Maher TM, Ming D, Abdullah R, de Lauretis A, Wickremasinghe M, et al. Rituximab in severe, treatmentrefractory interstitial lung disease. Respirology 2014;19:3539.

104. Chartrand S, Swigris JJ, Peykova L, Fischer A. Rituximab for the treatment of connective tissue disease-associated interstitial lung disease. Sarcoidosis Vasc Diffuse Lung Dis 2016;32:296-304.

105. Cohen JM, Miller A, Spiera H. Interstitial pneumonitis complicating rheumatoid arthritis. Sustained remission with azathioprine therapy. Chest 1977;72:521-4.

106. Mera-Varela A, Perez-Pampin E. Abatacept therapy in rheumatoid arthritis with interstitial lung disease. J Clin Rheumatol 2014;20:445-6.

107. Mohr M, Jacobi AM. Interstitial lung disease in rheumatoid arthritis: response to IL-6R blockade. Scand J Rheumatol 2011;40:400-1.

108. Dellaripa PF, Fry TA, Willoughby J, Arndt WF, Angelakis EJ, Campagna AC. The treatment of interstitial lung disease associated with rheumatoid arthritis with inflixima. Chest 2003;124:109S.

109. Marigliano B, Soriano A, Margiotta D, Vadacca M, Afeltra A. Lung involvement in connective tissue diseases: a comprehensive review and a focus on rheumatoid arthritis. Autoimmun Rev 2013;12:1076-84.

110. Ito I, Nagai S, Kitaichi M, Nicholson AG, Johkoh T, Noma $\mathrm{S}$, et al. Pulmonary manifestations of primary Sjogren's syndrome: a clinical, radiologic, and pathologic study. Am J Respir Crit Care Med 2005;171:632-8. 